\title{
ID36-DEVELOPMENT OF A LOW COST, SELF-CONFIGURING ADCP AND INTEGRATED DEPLOYMENT AND RECOVERY SYSTEM
}

\author{
DAVID W. VELASCO', CRISTOBAL MOLINA
}

1 Nortek Group. San Diego. USA

2 Nortek Group. Oslo. Norway

\begin{abstract}
Here we present the development of a short range ( 0.5 to $20 \mathrm{~m}$ ), low cost (< USD 5,000 ), three-beam, $1 \mathrm{MHz}$ acoustic Doppler current profiler called the Nortek ECO. The system employs a robust wideband velocity measurement technique where the only required user inputs are: 1) when deployment should start, 2) how often to sample, and 3) what is the water type. The hardware is highly portable, measuring only $130 \mathrm{~mm}$ tall by $85 \mathrm{~mm}$ in diameter and weighing 1.0 $\mathrm{kg}$ in air. It communicates externally with Bluetooth Low Energy technology and is powered by an embedded smart Li-lon battery that is charged by induction. Three independent activation methods are implemented, including Near-Field Communication, and all communication controlled via a platform-independent Progressive Web App. Coupled with the ADCP is a deployment and recovery system allowing for single person operation at depths up to $50 \mathrm{~m}$. Discussion of the system concept and design are presented, including sample data. This is an example for preparing the full paper that is identical with the extended summaries format. It must be written in Times New Roman.
\end{abstract}

\section{Keywords}

Portable ADCP, Shallow Water, Low Cost. 